\title{
Teaching graduate health policy via technology: A pilot study of engaged learning, social presence, and blended learning
}

\author{
June Wilson, Barbara Ganley \\ School of Health and Natural Sciences, Dominican University of California, San Rafael, USA. \\ Correspondence: June Wilson. Address: School of Health and Natural Sciences, Dominican University of California, San \\ Rafael, USA. Email: june.wilson@dominican.edu
}

Received: February 7, 2014

Accepted: May 12, 2014

Online Published: July 14, 2014

DOI : $10.5430 /$ jnep.v4n9p49

URL: http://dx.doi.org/10.5430/jnep.v4n9p49

\begin{abstract}
Purpose: This pilot study examined the relationship between engaged learning, social presence, and blended learning in a graduate nursing health policy course. The aims of the study were to: 1) determine the relationship between engaged learning, social presence and student satisfaction, and 2) investigate students’ perceived learning with online discussions and seminar blogs.

Results: Twenty-one participants completed adapted versions of the Social Presence and Satisfaction Scales. Overall there was a strong relationship between engaged learning, social presence, and student satisfaction.

Conclusions: Combining face-to-face classroom discussion with academically relevant assignments that engaged students in the health policy course was associated with an overall sense of satisfaction. The majority of participants reported that online discussions/blogs provided an opportunity to learn the "value of other points of view." Respondents also reported "greater collaboration working with colleagues with-in the blended model." Seventy-one percent of respondents reported they were "stimulated to do additional reading or research on topics discussed in the online portion of the class." The majority of respondents stated they "felt actively engaged with the course content working with-in the blended model." Instructor presence in the online component of the course was important for creating a sense of online community and student engagement.
\end{abstract}

\section{Key words}

Engaged learning, Blended learning, Satisfaction scale, Social presence, Blogs

\section{Background}

Learning is a “... relatively permanent change in mental processing, emotional functioning, and/or behavior as a result of experience. It is the lifelong, dynamic process by which individuals acquire new knowledge or skills and alter their thoughts, feelings, attitudes and actions” (p.52) ${ }^{[1]}$.

Learning is based on many factors, including individual learning style, pedagogical approach, and the technology or methodology used to deliver the information. Technology in the form of mobile devices, simulation, online software, and 
course management systems such as Blackboard ${ }^{\circledR}$ and Moodle ${ }^{\circledR}$ has radically changed how education is delivered. Students Google ${ }^{\circledR}$, text, email, Facebook ${ }^{\circledR}$, and tweet using social media, to stay connected and gain information. They seek support, reinforce relationships, seek advice, and advise each other. The availability of wireless technology propagates new ways of communicating and impacts not only our social engagement but how education outside of the classroom is delivered ${ }^{[2]}$. Students now have immediate access to material and information and the ability to engage with others from anywhere and to learn in a fashion that is most comfortable for them around the clock ${ }^{[3]}$. Courses that take advantage of these communication avenues combining face-to-face interaction with an online component allows for increased flexibility ${ }^{[4]}$ and better prepares students for the didactic classroom setting ${ }^{[5]}$. This will likely also enhance their community of inquiry and engagement with faculty and peers, improving their learning.

\subsection{Theoretical foundation}

Social Learning Theory is a perspective on learning that "includes personal characteristics of the learner, behavior patterns, and the environment” (p. 67) ${ }^{[1]}$. Learning is fortified by intrinsic factors, role models, and the external and internal reinforcement of behaviors. The active learners observe (and engage with) others and make decisions based on these observation and feedback (reinforcement). Shared social experiences and dialog, which give rise to a community of inquiry and social presence, enhance learning ${ }^{[1]}$.

Additionally, consider that each person has a unique blend of strengths and abilities, challenges, and emotional and intellectual intelligences. Howard Gardner ${ }^{[6]}$ posits that intelligence is not a single entity, rather it is comprised of nine basic intelligences, including: verbal-linguistic, logical/mathematical, bodily kinesthetic, spatial-visual, musical, interpersonal, intrapersonal, naturalistic, and existential. The linguistic learner may be good with oral presentations; the learner with strong logical or mathematical intelligence will see the patterns; the musical learner will detect the appreciation for sound; the bodily or kinesthetic learner will learn through body movement; the individual with good spatial visual intelligence will learn through images and space; the learner with strong interpersonal skills will relate well with others and will be more self-aware; the learner with an affinity for naturalistic intelligence will have an awareness of their natural environment; while the learner with an affinity to existential learning will tackle the deep human existence type questions (www.infed.org).

Teaching primarily consists of verbal-linguistic intelligence, while the other intelligences may be underutilized. Using multiple pedagogies such as online, and face-to-face interaction, and engaged activities, allows learners to engage in an environment best suited to them while challenging them to experience other ways of learning ${ }^{[3]}$. Using social learning theory as a means of augmenting multiple intelligences was a foundation for this study.

\subsection{Review of the literature}

\subsubsection{Search methods}

A review of the empirical literature was facilitated using EBSCO Host, Science Direct, ProQuest, PsycINFO, and PubMed. Search terms included engaged learning, blended learning, social presence, constructivist theory, blogging, multiple intelligence, and adult learning.

\subsubsection{Blended learning}

According to the Sloan Consortium ${ }^{[7]}$ there is a resurgence in interest surrounding blended learning. Online programs, including blended learning are deemed critical to the long-term strategy of many institutions, thus academic institutions will continue to improve the overall state of education through blended learning. There generally is no accepted definition of blended learning due in part to the varying ratios of online versus face-to-face learning ${ }^{[3]}$. Fundamentally blended learning is a combination of technology/media integrated with face-to-face and online learning designed to complement each other and promote learning for many learning styles ${ }^{[8]}$. It allows distance learners to both synchronously and asynchronously interact with their instructor and classmates ${ }^{[9]}$. What is not clear is the ideal ratio of online and 
face-to-face interaction that is needed for optimal learning ${ }^{[10]}$. Regardless of the ratio, the outcome data for this pedagogy is promising. There are several variables that contribute to these positive outcomes, including course structure, emotional support, and communication ${ }^{[9]}$. Blended pedagogy has been well researched and found to be an effective means of facilitating learning.

\subsubsection{Social presence and online learning}

Social presence was first introduced by the field of social psychology as the "the degree of salience of the other person in the interaction and the consequent salience of the interpersonal relationships" (p.65) ${ }^{[20]}$. It was later redefined as "the degree to which a person is perceived as a 'real person' in mediated communication” (p. 151) ${ }^{[21]}$. It is a construct that is influenced by two important factors: intimacy and immediacy ${ }^{[9,21]}$. Intimacy is dependent upon verbal and non-verbal cues such as physical distance, eye contact, and smiling, whereas immediacy is "the measure of the psychological distance that a communicator puts between himself or herself and the object of his/her communication" ( p. 9) ${ }^{[21]}$. Teacher immediacy and the presence of others are especially important factors in online education, in part because social presence facilitates trust and self-disclosure within an online environment ${ }^{[22]}$.

Gunawardena and Zittle ${ }^{[21]}$, pioneers in the area of social presence and computer-mediated conferencing, suggest that social presence is a reliable predictor of satisfaction. The benefits of social presence in the area of student satisfaction are well documented, and it must be established in order to initiate learning in the online environment ${ }^{[7,15]}$. Students who perceived a high level of collaborative learning also perceived high levels of social presence ${ }^{[9,21]}$. A sense of social presence or connectedness in the classroom was also related to engaged learning ${ }^{[19]}$.

A "community of inquiry" is important for successful engaged learning frameworks ${ }^{[11]}$. This community of inquiry includes in part, critical reflection, a high degree of uncertainty and tolerance, and a "trusting, respectful attitude of inquiry.” A key factor in the success of a blended learning program is the respect each member of the class has for each other, which encourages the expression of ideas without negative responses ${ }^{[11]}$.

Young and Bruce ${ }^{[19]}$ define engaged learning as the interest and motivation students have in their own learning. Student engagement is dependent upon several variables including the instructor's sense of connection with students and the creation of interesting, educational, and meaningful online activities ${ }^{[23]}$. Instructors who incorporate technology in the classroom can enhance student engagement and facilitate "higher levels" of learning ${ }^{\text {[24] }}$

\subsubsection{Technology and online learning}

The course management-system Moodle ${ }^{\circledR}$ is a powerful platform that allows synchronous and asynchronous learning to occur and it allows faculty to promote student engagement and peer interaction. However, while discussion boards can foster camaraderie, they may not be effective at deepening analytic and evaluative skills ${ }^{[24]}$. Blogs on the other hand can provide a sense of community and enhance learning through both student and instructor interaction ${ }^{[18]}$. Moodle ${ }^{\circledR}$ includes a blog component, which allows for the integration of blogs through engaged learning. Blogs are effective as the instructor can set up a topic and provide students with a forum whereby they can post comments, email links to the class, and monitor and participate in online discussion. Unlike discussion boards, blogs can be easily used on a handheld or mobile device, which allows instructors and students immediate engagement ${ }^{[24]}$. Blogs are an appealing way for educators to integrate computer-mediated communication tools at the university level ${ }^{[18]}$, and are an effective way to implement blended learning.

So and Brush ${ }^{[9]}$ examined the relationship between collaborative learning, social presence and satisfaction in a blended learning format and found that collaborating on a group project was associated with higher levels of perceived learning. Similarly, Goldman et al. ${ }^{[12]}$ utilized seminar blogs in a blended learning environment and found that blogs enhanced the learning and understanding of environmental health issues. Specifically, 60 graduate students in a public health class reported that the use of blogs enriched their learning experience, increased their interaction with others, and expanded their 
classroom learning. Over half of the group reported they learned from their peers, which may be indicative of the caliber of students in a graduate level course. Eighty percent of non-native speakers found it easier to write a comment or respond to another person than to speak aloud in class. Additionally, over $65 \%$ of students stated learning and using blogs was useful for current and future work, which implies that this is a skill that has good carry-over effects.

Halic et al. ${ }^{[18]}$ explored student perceptions of the effectiveness of blogs as an adjunct to lectures. Sixty seven undergraduate students were required to respond to a weekly post about class content, and respond to at least one peer comment for a total of 9 weeks. The majority of participants reported that their blog experience was positive as it enhanced their learning and led them to think about issues outside of the classroom, and to think about different perspectives. In addition, students who reported a higher sense of community also reported higher levels of learning.

\subsection{Purpose of the study}

The graduate nursing program at this university was developed with the working student in mind. Considering that hospital-based nurses generally work every other weekend, course work was initially offered on alternate weekends. Students stated they had a difficult time transitioning back and forth between course work, employment, and family obligations with the time laps between course engagement times. The challenge of keeping students engaged on the "off week” was very real. A blended learning model was therefore developed and piloted in several sections of one course.

The purpose of this study was to examine the complex relationship between engaged learning, social presence, and blended learning. The aims of this study were to: 1 ) determine the relationship between engaged learning, social presence, and student satisfaction; and 2) investigate students' perceived learning with online discussions and seminar blogs.

\subsection{Population of interest}

The participants in this pilot study were graduate nursing students enrolled in two sections of health care policy at a small university in northern California. The sample included 21 graduate nursing students.

\section{Methods}

\subsection{Ethics}

This project was approved by the University's Institutional Review Board for the Protection of Human Subjects. Students were required to attend the course and to complete the coursework, but completion of the surveys was voluntary. Information was provided about the study and consent was implied if one completed the survey. A faculty member who was not associated with the class administered the survey. Completing or not completing the survey in no way affected the student's grade.

\subsection{Procedures and assumptions}

The study examined a graduate-level blended-format course in two sections of Health Policy. There were several criteria for the course: a) students were required to post responses to weekly topics and respond to at least one peer, through a weekly blog via Moodle ${ }^{\circledR}$; b) students engaged in civic activities - for example wrote a letter to their congressman, or attended a public policy meeting and spoke during the open discussion period, and/or wrote an Op-Ed piece for the local newspaper; and c) students met every other week for face-to-face classroom discussion. The online blog and discussion, individual engaged activities, and classroom discussions were interwoven in order to provide a rich, comprehensive learning experience. All students who completed the health policy course were eligible to participate in this pilot study.

Students were approached at the completion of the course and invited to complete a paper and pencil survey about their satisfaction with working in a multi-modal, blended format. No identifying marks were on the surveys. Students were 
identified by a specific identification number only. Surveys were placed in a sealed envelope and the completed surveys were given to the individual responsible for data entry.

\subsection{Instruments}

The survey instrument was based on the social presence and satisfaction scales originally constructed by Gunawardena and Zittle ${ }^{[21]}$ and their research on social presence and satisfaction in computer-mediated environments. With permission from Dr. Charlotte Gunawardena, the scales were modified to adapt the language of the university environment rather than the GlobalEd environment as initially intended. The social presence scale was a 13-item Likert scale $(1=$ strongly disagree, 2 = disagree, 3 = unsure, $4=$ agree, and 5 = strongly agree). The student satisfaction scale was an 11-item Likert scale $(1=$ strongly disagree to $5=$ strongly agree). Students were asked to answer two open-ended questions that were reflective of their perceptions of benefits related to course material and their satisfaction with course content and learning ${ }^{[17]}$. Narrative data included: "Which aspects of this course was more beneficial to you and why? and "How satisfied were you with the course? For example, were your goals and/or expectations met? Please explain (e.g. were the course activities and assignments appropriate, was the content well-organized?” Additional data included age, gender, and past experience with online learning.

Reliability analysis was run for both the Social Presence Scale and the Satisfaction Scale with Cronbach's alpha of $a$ $=.964_{(13)}$ and $a=.959_{(11)}$ respectively. Validity was supported by expert review of the documents and comparison to the construct as defined by Gundawardena. External validity is limited because of the small and narrowly defined sample.

\subsection{Data collection and data analysis}

Students were asked to complete the demographics and surveys at the end of the semester. Completed surveys were placed in a sealed envelope and returned to the researcher. Data were analyzed using SPSS v.17 for Windows. Analysis included frequencies, descriptives, Cronbach’s alpha, correlation, and independent samples t-tests.

The two scales, satisfaction and social presence were collapsed to form two overall scores for analysis. Individual items were analyzed using correlation.

\section{Results}

\subsection{Demographics}

The group was primarily female (95.2\%). Ages were reported as 18-25 (14.3\%), 26-35 (28.6\%), 35-45 (19\%), and greater than 45 (38\%). Eighty percent of individuals stated they had completed at least one online course in the past. All had a Bachelor's degree in some field and at least one had an Associate degree in Nursing.

\subsection{Statistical findings}

There was no significant difference between the two groups in overall satisfaction and social presence even though there were two different instructors. There was an extremely high correlation between the two collapsed scales of Social Presence and Satisfaction at $r=.955$ for both $(p=.000, n=21)$. Table 1 details the responses for the Social Presence items and Table 2 details the responses for the Satisfaction items. Please note that, because of the small sample, strongly agree and agree were collapsed as were strongly disagree and disagree.

The mean, median, and standard deviation were evaluated for each of the 13 items in the Social Presence Scale. Maximum score for each item was five. Overall respondents were satisfied with the blended format class. Mean scores ranged from 3.48 ("online or web-based education is an excellent medium for social interaction") to 4.62 ("I felt comfortable 
interacting with other participants in the course”). The top two responses were related to comfort with the online format. Eighty-five percent of respondents reported they felt comfortable interacting with other students through this format.

Table 1. Social Presence Scale (percents)

\begin{tabular}{|c|c|c|c|c|c|}
\hline Line Item & Disagree/SD & Unsure & Agree/SA & Mean* & SD \\
\hline $\begin{array}{l}\text { Online or web-based education is an excellent medium for } \\
\text { social interaction. }\end{array}$ & 28.6 & 19 & 52.4 & 3.48 & 1.78 \\
\hline I felt comfortable conversing through this medium. & 23.8 & 14.3 & 61.9 & 3.76 & 1.73 \\
\hline $\begin{array}{l}\text { The introductions enabled me to form a sense of online } \\
\text { community. }\end{array}$ & 28.6 & 14.3 & 57.1 & 3.57 & 1.80 \\
\hline The instructor created a feeling of an online community. & 28.6 & 14.3 & 57.1 & 4.05 & 1.50 \\
\hline $\begin{array}{l}\text { I felt comfortable participating in the online course } \\
\text { discussions. }\end{array}$ & 4.8 & 23.8 & 71.4 & 4.33 & 1.15 \\
\hline The instructor facilitated discussions on the course. & 14.3 & 19.0 & 66.7 & 4.05 & 1.50 \\
\hline $\begin{array}{l}\text { I felt comfortable interacting with other participants in the } \\
\text { course. }\end{array}$ & 4.8 & 9.5 & 85.7 & 4.62 & 1.02 \\
\hline $\begin{array}{l}\text { I felt that my point of view was acknowledged by other } \\
\text { participants. }\end{array}$ & 19.0 & 9.5 & 71.4 & 4.05 & 1.63 \\
\hline $\begin{array}{l}\text { I was able to form distinctive individual impressions of some } \\
\text { course participants. }\end{array}$ & 9.5 & 23.8 & 66.7 & 4.14 & 1.35 \\
\hline $\begin{array}{l}\text { My level of learning that took place in this course was the } \\
\text { highest quality. }\end{array}$ & 14.3 & 23.8 & 61.9 & 3.95 & 1.50 \\
\hline Overall the instructor for this course met my expectations. & 14.3 & 9.5 & 76.2 & 3.85 & 1.49 \\
\hline $\begin{array}{l}\text { Discussions using the medium of online postings are more } \\
\text { impersonal than face-to-face discussions. }\end{array}$ & 14.3 & 19.0 & 66.7 & 4.24 & 1.48 \\
\hline
\end{tabular}

Note. All scores ranged from 1.00 to 5.00

* 1 = Strongly Disagree, 2 = Disagree, 3 = Unsure, 4 = Agree, 5 = Strongly Agree

Table 2. Satisfaction (percents)

\begin{tabular}{|c|c|c|c|c|c|}
\hline Line Item & Disagree/SD & Unsure & Agree/SA & Mean* & SD \\
\hline I was able to learn through the medium of online posting. & 4.8 & 28.6 & 66.7 & 4.24 & 1.8 \\
\hline I was able to learn from the online discussions. & 4.8 & 23.5 & 71.4 & 4.33 & 1.55 \\
\hline $\begin{array}{l}\text { I was stimulated to do additional reading or research on topics } \\
\text { discussed in the online portion of the course. }\end{array}$ & 14.3 & 14.3 & 71.4 & 4.14 & 1.49 \\
\hline I learned to value other points of view. & 9.5 & 4.8 & 85.7 & 4.52 & 1.25 \\
\hline $\begin{array}{l}\text { As a result of my experience with the online nursing course, I } \\
\text { would like to participate in another blended course. }\end{array}$ & 23.8 & 19.0 & 57.1 & 3.67 & 1.71 \\
\hline The online part of this course was a useful learning experience. & 19.0 & 19.0 & 61.9 & 3.86 & 1.62 \\
\hline $\begin{array}{l}\text { I feel I learned more in this blended course than I would have in } \\
\text { a traditional classroom setting. }\end{array}$ & 23.8 & 28.6 & 47.6 & 3.47 & 1.66 \\
\hline $\begin{array}{l}\text { The diversity of topics in the online course prompted me to } \\
\text { participate in discussions. }\end{array}$ & 9.5 & 23.8 & 66.7 & 4.14 & 1.35 \\
\hline $\begin{array}{l}\text { I put a great deal of effort into learning how to post online in } \\
\text { order to participate in the online discussion. }\end{array}$ & 23.8 & 14.3 & 61.9 & 3.76 & 1.73 \\
\hline $\begin{array}{l}\text { I felt actively engaged with the course content working with the } \\
\text { blended model. }\end{array}$ & 23.8 & 19.0 & 57.1 & 3.67 & 1.71 \\
\hline $\begin{array}{l}\text { I felt greater collaboration with my colleagues working within } \\
\text { the blended content. }\end{array}$ & 23.8 & 9.5 & 66.7 & 3.86 & 1.74 \\
\hline
\end{tabular}

Note. all scores ranged from 1.00 to 5.00

* 1 = Strongly Disagree, 2 = Disagree, 3 = Unsure, 4 = Agree, 5 = Strongly Agree 
The mean, median, and standard deviation for the social presence scale were evaluated for each of the 11 items of the Satisfaction scale. Maximum score for each item was five. The top item was "I learned to value other points of view" (4.52), followed by "I was able to learn from the online discussions" (4.33) and "I was stimulated to do additional reading or research on topics discussed in the online portion of the course" (4.15).

There were three main factors from the satisfaction scale that correlated highly with elements of the social presence scale; 1) the creation of an online community, 2) diversity of topics, and 3) facilitator discussion. High correlations were found for "The instructor created a feeling of online community" and "The online part of the course was a useful learning experience ( $r=.93)$; "The diversity of topics in the online course prompted me to participate in the discussion $(r=.86)$; and "I felt actively engaged with the course content working within the blended model $(r=.88)$.

Diversity of topics was also an important element for overall satisfaction. The item "The diversity of topics in the online course prompted me to participate in the discussions" correlated highly with "I felt instructor facilitated discussions on the course” ( $r=.86$ ), and "overall the online part of the course met my learning objectives” ( $r=.88)$.

The item "The instructor facilitated discussions on the course" correlated highly with "I was able to learn through the medium of online posting ( $r=.81$ ), "the online part of the course was a useful learning experience ( $r=.93)$, "the diversity of topics in the online course prompted me to participate in discussion" $(r=.86)$, and "I felt actively engaged with the course content working within the blended model $(r=.88)$.

\subsection{Narrative responses}

Two narrative questions assessed how beneficial this course was to student leaning, and overall satisfaction with course pedagogy. The qualitative data from the open-ended questions reinforced the findings from the quantitative data analysis. The responses to the question "Which aspect of this course was more beneficial to you and why?" were overwhelmingly positive. One respondent enjoyed the "different types of course activities," while another stated she enjoyed "getting involved with local community activities." Several respondents reported a sense of political awareness as noted in the response "I really enjoyed this class. I feel I have been more political and aware of my community." One woman stated "The online discussion was beneficial to me, but at the same time it was easy to overlook." Another reported "I prefer face to face interaction, but online aspects allow for more in-depth research and conversation [sic] is more convenient.”

The responses to the question "How satisfied were you with the course?" were overall positive. "I learned lots of information in the health care field" “... it stretched my mind." "It expanded my knowledge and broadened my understanding of health care and politics" "... inspired me to think outside of the box and pushed me out of my comfort zone.” and "the blended structure of the class worked well.” Not all were satisfied with the asynchronous learning format. One respondent stated: "Because things were posted at different times, it was difficult to follow the conversations".

\section{Discussion and conclusions}

Blended learning is a flexible approach to learning that transcends time and place while offering an asynchronous learning environment, simultaneously maintaining the benefits of the face-to-face interaction. Blended learning has the potential to engage students in critical thinking, and reflective experiences ${ }^{[2,10,11]}$; leads to personal and professional growth ${ }^{[12,13]}$; allows interaction and engagement with other students and faculty ${ }^{[9,12]}$ and encourages openness and tolerance for other's ideas as well as a respectful attitude of inquiry ${ }^{[12]}$.

Among this group there was a strong relationship between engaged learning, social presence, and student satisfaction. More specifically, combining face-to-face classroom discussion and online interactive activities, with academically relevant assignments, engaged students in the course content and was associated with an overall sense of satisfaction. This relationship between online discussion and satisfaction has been found with other cohorts of nursing students ${ }^{\text {[27] }}$. 
These students felt a sense of safety in this community inquiry and developed trust and respect for each other; there was an ability to express one's self without feeling vulnerable. This sense of community was reinforced by the social presence which came from being able to exchange ideas and information in this safe environment in class and online at any time of the day or night. Also, the majority of students reported that the online discussion provided an real opportunity to learn from others and hear others' perspectives which is consistent with past research ${ }^{[12,16,18]}$; it motivated them to do additional readings and to be more engaged with their peers. They felt more connected with their classmates. Study participants were engaged in their learning and the overwhelming majority of respondents stated their point of view was acknowledged by others. One student reported being inspired to think outside of the box and being pushed to work outside of her comfort zone. Students also reported a sense of "connectedness" as opposed to isolation. Others studies support this and have found that combining face-to-face meetings, with clinically relevant assignments and discussion boards may prepare students for lifelong learning ${ }^{[13]}$.

This being said, the onus of ensuring engagement among the students is on the faculty who must be available and engaged in the work along with the students. Technology, provides educators the ability to actively engage students with course content, to move students from teacher-centered to student-centered learning ${ }^{[27]}$. As students move towards studentcentered learning, they purposefully engage with one another and are open to others' ideas and interpretations ${ }^{[11]}$.

The aims of this pilot study were twofold. Firstly, we sought to determine the relationship between engaged learning, social presence, and blended learning. There was active involvement with course content when there was a sense of social presence; specifically, facilitation of an online community was important for engagement with course content within the blended model. Secondly, we sought to investigate students' perceived learning with online discussions and seminar blogs. Facilitator involvement was extremely important. Students were stimulated to do additional readings or research topics discussed in the online component of the course if the instructor facilitated discussions, and when students felt that their point of view was acknowledged by other participants.

Over $85 \%$ of students stated they felt comfortable interacting with other participants in the course. This finding is consistent with Cobb ${ }^{[27]}$ who found that the majority of participants felt comfortable interacting in a blended learning format. It is important that participants know they can post a discussion without fear of negative responses from others as this encourages a community of inquiry ${ }^{[11]}$. Online discussion also gives the learner for whom English is a second language, time to consider his or her response and to formulate a logical and coherent response rather than trying to think of just the right words in an immediate environment.

Blended learning is a positive way for graduate students to learn. It provides students the ability to connect with their professor and their peers, as well as learn through creative reflection and discourse ${ }^{[28]}$. This pilot study supports Social Learning Theory where environment, interaction, intrinsic factors, motivation, and reinforcement are clear aspects of the blended learning environment.

\section{Practical implications}

As the opportunity for blended learning grows, nursing faculty need to be provided with adequate professional development so they can teach online ${ }^{[19]}$. In this study, the online discussion involved online blogs and was carried over to the face-to-face discussion the following week. The interface of the two forms of learning should come together seamlessly and time must be provided for participants to discuss the online content in a face-to-face setting ${ }^{[5]}$.

While blended learning is not new in academe, it is a way to help students learn in an environment where one-size does not fit all ${ }^{[29]}$. The academic horizon is changing; learning takes place online, in groups, individually, by facing, tweeting, Moodling, and Googling. Students no longer accept outdated pedagogical practices. As learning is a dynamic process, 
faculty and universities need to be dynamic in how learning is facilitated. Using blended learning is simply one way to support the students and enhance learning well into the future.

\section{Limitations}

The main limitation of this pilot study is the small sample size and convenience sampling technique. The time frame for the study was also relatively short (16 weeks), which is the length of a traditional semester. Since students interacted with each other online on a bi-monthly basis, this short time frame may have been too brief a period to fully determine the capacity of group dynamics and social presence through online discussion ${ }^{[12]}$.

This study also utilized self-reports and the effects of blended learning were not specifically measured with a comparison group. Similarly, overall satisfaction was measured with the Satisfaction Scale ${ }^{[21]}$, yet specific questions about blogs themselves were not addressed. It may be helpful to address which specific variables impact perceived learning.

Technology has allowed us to move forward with how we educate our future nurses. Programs that use blended learning are measuring positive effects, including increased flexibility ${ }^{[4]}$, better preparation for the didactic classroom setting ${ }^{[5]}$, openness and tolerance for others' ideas, and a respectful attitude of inquiry ${ }^{[13,14]}$. As technological advances continue to improve, it will be imperative that education utilize what is available in order that we continually improve our nursing education to meet the demands of the changing health care system.

\section{References}

[1] Bastable SB. Nurse as educator: Principles of teaching and learning for nursing practice. Boston, MA: Jones and Bartlett Publishers; 2008.

[2] Bassendowski SL, Petruck P, Salgado A. Designing a “concept capture” template: Using a multi-media model for learner engagement. The International Journal of Technology, Knowledge and Society. 2010; 6: 93-99.

[3] Picciano AG. Blended with purpose: The multimodal model. Journal of Asynchronous Learning Networks. 2009; 13(1): 7-19.

[4] Carroll B. Going hybrid: Online course components increase flexibility of on-campus courses. Online Classroom. 2003: 4-7. PMid:15484550

[5] Glogowska M, Young P, Lockyer L, Moule P. How 'blended' is blended learning?: Students' perceptions of issues around the integration of online and face-to-face learning in a continuing professional development (CPD) health care context. Nurse Education Today. 2011; 31: 887-891. PMid:21388722 http://dx.doi.org/10.1016/j.nedt.2011.02.003

[6] Gardner H. Frames of mind: The theory of multiple intelligences. New York: Basic Books; 1983. Available from: http://www.infed.org/thinkers/gardner.htm

[7] Sloan Consortium. Blending In: The extent and promise of blended education in the United States 2010. Available from: http://sloanconsortium.org/publications/survey/blended06

[8] Singh H. Building effective blended learning programs. Educational Technology. 2003; 43(6): 51-54.

[9] So HJ, Brush TA. Student perceptions of collaborative learning, social presence and satisfaction in a blended learning environment: Relationships and critical factors. Computers and Education. 2008: 51(1): 318-336. http://dx.doi.org/10.1016/j.compedu.2007.05.009

[10] Garrison DR, Kanuka H. Blended learning: Uncovering its transformative potential in higher education. Internet and Higher Education. 2004; 7: 95-105. http://dx.doi.org/10.1016/j.iheduc.2004.02.001

[11] Peters J, Taylor J, Doi M. Reflections on three types of teaching and learning in a model-based, blended online course. The International Journal of Learning. 2011; 18(2): 357-366.

[12] Godlman RH, Cohen AP Sheahan F. Using seminar blogs to enhance student participation in learning in public health school classes. American Journal of Public Health. 2008: 98(9): 1658-1663. PMid:18633075 http://dx.doi.org/10.2105/AJPH.2008.133694

[13] Johansen E, Harding T, Ljosaa, TM. Norwegian nurses’ experiences with blended learning: An evaluation study. International Journal of Media, Technology, and Lifelong Learning. 2012; 8(1): 54-70. 
[14] United States Department of Education. Evaluation of evidence-based practices in online learning; nd. Available from: http://www2ed.gov/rschstat/eval/tech/evidence-based-practices/finalreport.pdf

[15] Aragon SR. Creating social presence in online environments. New Direction for adult and Continuing Education, 2003; 100: 57-68. http://dx.doi.org/10.1002/ace.119

[16] Gunawardena CN. Social presence theory and implications for interaction and collaborative learning in computer conferences. Journal of Educational Tellecommunications. 1995; 1(2/3): 147-166.

[17] Richardson JC, Swan K. Examining social presence in online courses in relation to students' perceived learning and satisfaction. Journal of Asynchronous Learning. 2003; 7(1): 68-88.

[18] Halic O, Lee D, Paulus T, Spense M. To blog or not to blog: Student perceptions of blog effectiveness for learning in a college-level course. The Internet and Higher Education. 2010; 13(4): 206-213. http://dx.doi.org/10.1016/j.iheduc.2010.04.001

[19] Young S, Bruce MA. Classroom community and student engagement in online courses. Journal of Online Learning and Teaching. 2011; 7(2): 219-230.

[20] Short J, Williams E, Christie A. The social psychology of telecommunications. London, John Wiley \& Sons; 1976.

[21] Gunawardena CN, Zittle, FJ. Social presence as a predictor of satisfaction within a computer-mediated conferencing environment. The American Journal of Distance Education. 1997; 11(3): 8-26. http://dx.doi.org/10.1080/08923649709526970

[22] Gunawardena CN, Nolla AC, Wilson PL, Lopez-Islas JR, Ramirez-Agnel N, Megchun-Alpizar RM. A cross-cultural study of group process and development in online conferences. Distance Education. 2002; 22(1): 85-121. http://dx.doi.org/10.1080/0158791010220106

[23] Mandernach BJ. Three ways to improve student engagement in the online classroom 2009. Available from: http://www.vcu.edu/cte/resources/newsletters_archive/OC0903.pdf

[24] Revere L, Kovach JV. Online technologies for engaged learning. The Quarterly Review of Distance Education. 2003; 12(2): 113-124.

[25] Dziuban C, Moskal P, Hartman J. Higher education, blended learning and the generations: Knowledge is power—no more. Elements of quality online education: Engaging communities. Needham, MA: Sloan Center for Online Education; 2005. PMid:15835788

[26] Liu X, Magjuka RJ, Bonk CJ, Lee S. Does sense of community matter? An examination of participants’ perceptions of building learning communities in online courses. The Quarterly Review of Distance Education. 2007; 8(1): 9-24.

[27] Stanley MJC, Dougherty JP. A paradigm shift in nursing education: A new model. Nursing Education Perspectives. 2010; 31(6): 378-380. PMid:21280445

[28] Cobb SC.Social presence and online learning: A current view from a research perspective. Journal of Interactive Online Learning. 2009; 8(1).

[29] Selingo JJ. College (un) bound: the future of higher education and what it means for Computers \& Education. 2008; 51(1): 318-336. 